\title{
Injury to Diaphragm with Open Wound into Cavity
}

National Cancer Institute

\section{Source}

National Cancer Institute. Injury to Diaphragm with Open Wound into Cavity. NCI

Thesaurus. Code C35234.

Trauma to the diaphragm associated with a break in the tissue that extends into the thoracic cavity. 